\title{
An Intermediate Complexity Climate Model (ICCMp1) based on the GFDL flexible modelling system
}

\author{
R. Farneti and G. K. Vallis \\ GFDL/AOS Program, Princeton University, Princeton, New Jersey, USA \\ Received: 26 March 2009 - Published in Geosci. Model Dev. Discuss.: 22 April 2009 \\ Revised: 7 July 2009 - Accepted: 10 July 2009 - Published: 21 July 2009
}

\begin{abstract}
An intermediate complexity coupled oceanatmosphere-land-ice model, based on the Geophysical Fluid Dynamics Laboratory (GFDL) Flexible Modelling System (FMS), has been developed to study mechanisms of oceanatmosphere interactions and natural climate variability at interannual to interdecadal and longer time scales. The model uses the three-dimensional primitive equations for both ocean and atmosphere but is simplified from a "state of the art" coupled model by using simplified atmospheric physics and parameterisation schemes. These simplifications provide considerable savings in computational expense and, perhaps more importantly, allow mechanisms to be investigated more cleanly and thoroughly than with a more elaborate model. For example, the model allows integrations of several millennia as well as broad parameter studies. For the ocean, the model uses the free surface primitive equations Modular Ocean Model (MOM) and the GFDL/FMS sea-ice model (SIS) is coupled to the oceanic grid. The atmospheric component consists of the FMS B-grid moist primitive equations atmospheric dynamical core with highly simplified physical parameterisations. A simple bucket model is implemented for our idealised land following the GFDL/FMS Land model. The model is supported within the standard MOM releases as one of its many test cases and the source code is thus freely available. Here we describe the model components and present a climatology of coupled simulations achieved with two different geometrical configurations. Throughout the paper, we give a flavour of the potential for this model to be a powerful tool for the climate modelling community by mentioning a wide range of studies that are currently being explored.
\end{abstract}

Correspondence to: R. Farneti

(riccardo.farneti@noaa.gov)

\section{Introduction}

The study and modelling of the coupled ocean-atmosphere system at interannual and longer timescales leads us to a difficult choice between working with a high-complexity model or an idealised/analytical framework. Although both approaches are undoubtedly synergetic, one modelling philosophy might be more useful depending on the questions one is asking. The most realistic tools for the study of climate variability and change are state-of-the-art, "IPCC-class" coupled general circulation models (CGCMs); however, these models also carry a heavy computational burden and the identification of a particular mechanism or cause-and-effect pathway in the climate system becomes difficult to discern. At the other extreme, one may construct very idealised models that allow for several century-long integrations and ensemble runs, permitting parameter dependency studies and tests with different configurations. However, if the models are oversimplified their relevance to the real climate system becomes at issue, for they may neglect crucial dynamics important to coupled variability, so that care must be taken in their interpretation and use.

So far, idealised coupled models have generally been lacking a dynamical atmospheric component, focusing on coupling a fully-dynamical ocean to an atmosphere of different degree of simplification, from Energy Balance Models (EBM) to statistical-dynamical models (Saravanan and McWilliams, 1995, 1997; Fanning and Weaver, 1997; Kamenkovich et al., 2000b, 2002; Kravtsov and Ghil, 2004; Montoya et al., 2005), or opting for a simplified physical framework as in Quasi-Geostrophic (QG) dynamics (Kravtsov and Robertson, 2002; Hogg et al., 2003; Kravtsov et al., 2007).

Published by Copernicus Publications on behalf of the European Geosciences Union. 
Here, we propose a climate model of intermediate complexity composed of dynamical ocean-atmosphere-ice components, which are simplified by using idealised and more economical physics packages and making simplifications in the geometry of the configurations. A few similar models exist, for example FORTE (Smith et al., 2006), FAMOUS (Smith et al., 2008), SPEEDO (Hazeleger et al., 2003), ECBILT (Opsteegh et al., 1998) and the aquaplanet model of Marshall et al. (2007). However, our model and approach differ from these in a couple of important respects. First, the model presented here is directly derived from and remains closely related to the IPCC-class GFDL coupled climate model. Thus, in terms of a modelling hierarchy, it makes a direct connection to a high-end model. Held (2005) pointed out the need for model hierarchies to achieve a better understanding of climate dynamics, and we strongly advocate this philosophy. Second, our model has physics that is even simpler than those above mentioned, so allowing us to focus on dynamical mechanisms of variability.

The coupled model, called the Intermediate Complexity Climate Model (ICCM), is a simplified version of the Geophysical Fluid Dynamics Laboratory (GFDL) CM2.0, and is based on the Flexible Modelling System (FMS; http://www. gfdl.noaa.gov/fms/). Two geometrical versions are described here (although the coupled model is in no means restricted to these): a sector, or Atlantic, and a global, or Aquaworld ${ }^{1}$, configuration.

In the first case our ocean component is that of a single ocean basin (Atlantic-like) with an Antarctic Circumpolar Current simulated by cyclic open boundary conditions. The most striking simplification of our model's Atlantic configuration is in its geometry; we decided to focus on basinscale ocean-atmosphere interactions and therefore opted for a sector model, in which the ocean is represented by a single basin and the atmosphere above it is a $120^{\circ}$ sector. This has some similarities with the QG framework proposed by Hogg et al. (2003) and the modelling strategy of Saravanan and McWilliams (1995, 1997), where a 2-D zonally averaged ocean sector model is used together with a dynamical idealised atmosphere. Several experiments have been performed with this configuration in which the geometry (e.g., closed Drake Passage, wider or shallower ocean basin) or a parameter/parameterisation was altered (e.g., laplacian horizontal diffusivity scheme for tracers, oceanic vertical diffusivity, atmospheric moisture content, solar radiation and rotation rate) and they are the subject of separate studies. The second configuration, Aquaworld, is that of a $360^{\circ}$ atmosphere overlying a dynamic ocean where no continents are present and only polar islands of $10^{\circ}$ in latitude are included due to the sea-ice model necessity of a land grid point. This set-up re-

\footnotetext{
${ }^{1}$ We intentionally make a distinction between "Aquaplanet", that in the atmospheric literature refers to an atmospheric model overlying a mixed-layer ocean with no continents, and Aquaworld, where a dynamic ocean is present.
}

sembles the models presented in Smith et al. (2006) and Marshall et al. (2007). Both configurations incorporate the eddy parameterisation of Gent-McWilliams (hereafter GM; Gent and McWilliams, 1990; Griffies, 1998), which is believed to improve convection in coarse-resolution ocean models. A constant value is used for the vertical diffusivity in the ocean, $\kappa_{v}$, in order to clearly explore dependencies on this parameter. Idealised initial temperature and salinity conditions are applied to the ocean at rest and the sea-ice model is coupled to the ocean.

The moist primitive equations atmospheric component employs simplified parameterisations of atmospheric processes following Frierson (2005). Namely, i) the use of gray radiative transfer, ii) a large-scale condensation scheme, iii) a simplified Betts-Miller convection scheme and iv) a simplified Monin-Obukhov boundary layer scheme. These changes imply a considerable computational gain, retaining a good representation of the atmospheric climate at both tropical and extra-tropical latitudes (Frierson et al., 2006). Moreover, the flexibility and simplification of the atmospheric physics have already been tested in a suite of different settings, from studies of extra-solar planets (Mitchell et al., 2006) to the use in non-hydrostatic dynamical cores (Garner et al., 2007).

Finally, the land model is reduced to a single bucket land, with constant water availability and heat capacity, and a simple redistribution of precipitated water back into the ocean. The model components and new parameterisations retain the original modularity, in order to allow the coupled model to recover complexity in any of its parts.

It should be emphasised at this point that the objectives of this modelling initiative are not those of reproducing an accurate climate in all its details, but rather to test some mechanisms in the coupled ocean-atmosphere system and try to understand the relative role of its different components. The speed and idealised physics of the dynamical components of ICCM make it suitable for long integrations in an attempt to elucidate some of the basic phenomena involved in air-sea interactions. In fact, a wide range of geometrical and parameter space settings are presently being used to investigate a variety of problems: the decadal variability of the meridional overturning circulation (MOC) and its link to intrinsic modes of atmospheric variability (e.g., the North Atlantic Oscillation), the partitioning of the heat transports in the ocean and atmosphere, Atlantic equatorial variability, Earth's climate sensitivity and the biogeochemical response to ocean circulation variability and changes.

\section{The model formulation}

\subsection{The ocean component}

The ocean component of ICCMp1 is the $4 \mathrm{p} 1$ version of the free surface primitive equations Modular Ocean Model MOM (Griffies et al., 2004, 2005). The oceanic physics is 
unchanged from the standard MOM model, and the main modifications are in the general geometry and geography of the ocean component.

The horizontal transport of tracers is parameterised by the GM type of eddy parameterisation and an along isopycnal diffusion of tracers (Griffies, 1998). The mixing of tracers is accomplished by a constant vertical diffusivity $\kappa_{v}$, with no background horizontal diffusion except in the upper mixed layer. We opted for a vertically and latitudinally uniform coefficient for ease of analysis, interpretation and sensitivity tests. Similarly, constant horizontal, $v_{h}$, and vertical, $v_{v}$, momentum viscosities are used.

Within the same grid, the full GFDL dynamicthermodynamic sea-ice model (Winton, 2000) is coupled to the ocean. Because of reasons stated below in the description of the atmospheric model, the ocean albedo was set to a high, but consistent with radiative fluxes, constant value of 0.33 . Idealised initial conditions for temperature and salinity were applied to the ocean at rest and the model was spun-up for several millennia. The model is now part of the GFDL FMS repository and will be thus supported and developed for future releases; ICCMp1 can be freely obtained with each standard release of the ocean model MOM.

\subsection{The atmospheric component}

Most coupled models of intermediate complexity have focused on rather overly-simplified atmospheric models, generally consisting of an energy balance atmosphere with specified fluxes of heat, moisture and momentum, or a twodimensional zonally averaged statistical-dynamical atmosphere (see for example Fanning and Weaver, 1997; Kamenkovich et al., 2000b, 2002; Montoya et al., 2005).

Here, we opt for a fully dynamical moist atmospheric model, in which the simplifications comes from the physics formulation. Simplified physical parameterisations (Frierson, 2005; Frierson et al., 2006, 2007; Frierson, 2007) have been adapted to the GFDL moist primitive equations model using the B-grid atmospheric dynamical core (The GFDL Global Atmospheric Model Development Team, 2005), resulting in an extremely computationally efficient model. A similar line of thought is present in the Speedy model of Molteni (2003), where a spectral model is used with simplified physical parameterisations; however, we believe our choice of using the GFDL dynamical core is more consistent with an idea of modularity, in order to allow the coupled model to recover complexity in any of its parts if needed and, ideally, be compared to the full GFDL CM2.1 coupled model (Delworth et al., 2006) variability and air-sea interactions.

The simplified atmospheric model presents the following key parameterisations:

1. For infra-red radiative transfer, a grey radiation scheme is used with fluxes that are a function only of temperature, and not water vapour or cloudiness. Both a seasonal and diurnal cycle can be switched on in the model.
Table 1. Ocean, atmosphere and land main parameters for the Control experiment. Diffusivity and viscosity values are given in $\mathrm{m}^{2} \mathrm{~s}^{-1}$. The vertical diffusivity $\kappa_{v}$ parameter will be changed in the Kv-Experiments. When GM is used the horizontal diffusivity $\kappa_{h}$ is set to zero.

\begin{tabular}{lll}
\hline Parameter & Value & Description \\
\hline Ocean & & \\
$L^{o}$ & 24 & $\mathrm{~N}^{o}$ of levels \\
$\Delta x$ & $2 \times 2^{\circ}$ & Horizontal grid spacing \\
$(\lambda, \phi)$ & $60^{\circ} \times 140^{\circ}$ & Domain size \\
$\alpha^{o}$ & 0.33 & Ocean albedo \\
$\alpha^{i}$ & 0.45 & Ice albedo \\
$\kappa_{h}$ & $0.8 \times 10^{3}$ & Horizontal diffusivity \\
$\kappa_{i}$ & $0.8 \times 10^{3}$ & Isopycnal diffusivity \\
$\kappa_{t}$ & $0.8 \times 10^{3}$ & Thickness diffusivity \\
$\nu_{h}$ & $1 \times 10^{5}$ & Horizontal viscosity \\
$\kappa_{v}$ & $0.5 \times 10^{-4}$ & Vertical diffusivity \\
$\nu_{v}$ & $1 \times 10^{-3}$ & Vertical viscosity \\
\hline Atmosphere & 7 & \\
$L^{a}$ & $7.75^{\circ} \times 3^{\circ}$ & Horizontal grid spacing \\
$\Delta x$ & $120^{\circ} \times 168^{\circ}$ & Domain size \\
$(\lambda, \phi)$ & 1360 & Solar Flux [W m $\left.{ }^{-2}\right]$ \\
$F^{s o l}$ & 1.2 & Solar Gradient \\
$\Delta_{s o l}$ & & \\
\hline Land $^{l}$ & 0.45 & Land albedo \\
$\alpha^{l}$ & $1 \times 10^{5}$ & Soil Heat capacity [J K $\left.\mathrm{K}^{-1} \mathrm{~m}^{-2}\right]$ \\
$C_{p}^{l}$ & & \\
\hline
\end{tabular}

However, the benchmark configuration is the one chosen to reproduce the observed annual and zonal mean top of the atmosphere (TOA) net shortwave flux, and in that case the solar flux is given by

$F^{\mathrm{sol}}=\frac{R_{\mathrm{sol}}}{4}\left\{1.0+\Delta_{\mathrm{sol}} \frac{\left(1-3 \mu^{2}\right)}{4}\right\}$,

where $R_{\text {sol }}$ is the global mean solar flux, $\Delta_{\text {sol }}$ the meridional solar gradient and $\mu$ is sine-latitude (see Table 1). For simplicity we also neglect solar absorption in the atmosphere, and we thus rely on surface albedo to represent the total planetary albedo.

2. A large-scale condensation (LSC) scheme is used in conjunction with a simplified Betts-Miller (SBM) convection scheme (Betts, 1986; Betts and Miller, 1986). Humidity and temperature are adjusted where largescale saturation occurs and precipitation falls out immediately in its liquid phase only; the SBM convection scheme relax temperature and humidity to a specified post-convective reference profile. Frierson (2007) shows that the inclusion of the SBM scheme provides and overall stabilizing influence over the Tropics, with a greater poleward energy transport by the mean flow, a 
weaker mass transport by the Hadley cells and a reduction in the dependency on horizontal resolution. Water vapour itself is a prognostic variable, but there is no liquid water or clouds: liquid water substance all falls to the surface as rain immediately upon condensation, which occurs at saturation and with a corresponding adjustment of temperature, preserving energy (Frierson et al., 2006).

3. A simplified Monin-Obukhov similarity theory for the computation of surface fluxes and a boundary layer scheme linked to the drag coefficients calculation was implemented in order to mediate the boundary layer fluxes in the model.

At present, the model does not incorporate trace gases nor clouds, making it unsuitable for climate change studies. However, we envisage in the near future the inclusion of an improved radiation scheme similar to the one developed in Molteni (2003). For a more detailed description of the physical parametrizations we refer the reader to Frierson (2005) (available at: www.atmos.washington.edu/ dargan/ papers/thesis.pdf). We would like to stress at this point that all model modifications have been implemented in a modular way, that is, it is possible to switch back to the "full-physics" parameterisations with a simple namelist change. Modules that have been modified or added to the FMS B-grid atmospheric model are listed in Table 2.

\subsection{The land component}

The GFDL Land model (LM2.0; Milly and Shmakin, 2002) is implemented as a single "bucket" soil water reservoir. Liquid water capacity of each land cell is gathered into a single soil water reservoir, and constant values of water availability, heat capacity, roughness and drag coefficients are used. Rain can accumulate in the soil to a maximum prescribed soil moisture content (i.e., water availability). When precipitation exceeds the prescribed water capacity, a very simple basin map collects the precipitated water and idealised rivers redistribute the water back into the ocean at the nearest point. The advantages of such bucket land are the closure of the water budget compared to a swamp and the simplification of land/sea effects on the precipitation-minus-evaporation flux. On the other hand, in some places - notably the equatorial regions - the land reaches high temperatures, which must be damped by an artificially high constant albedo (0.45). Presently there is no orography in the model and glaciers are not allowed to form, as all precipitated water stays in its liquid form.

\section{The Atlantic configuration}

We will firstly present the climate of our most tested and used configuration, where the focus is on a single basin ocean cou-
Table 2. New and modified modules in the B-grid atmospheric component.

New modules:
/atmos_param/betts_miller/
/atmos_param/grey_radiation/
/atmos_param/lscale_cond/
/atmos_param/moist_conv/
/atmos_param/diffusivity/
Modified modules:
/atmos_bgrid/tools/bgrid_cold_start.F90
/atmos_param/moist_processes/moist_processes.F90
/atmos_param/monin_obukhov/monin_obukhov.F90/
/atmos_param/physics_driver/physics_driver.F90
/atmos_param/vert_diff_driver/vert_diff_driver.F90
/atmos_param/vert_turb_driver/vert_turb_driver.F90
/shared/constants/constants.F90
/shared/sat_vapor_pres.F90
/shared/sat_vapor_pres_k.F90

pled to a sector atmosphere: the Atlantic configuration. Sector coupled models can be very useful in identifying basinscale processes, air-sea interactions and dynamical responses to local and remote perturbations in the climate system. The kind of idealised model presented here should be used as a tool for testing simple theoretical arguments or complicated responses emerging from CGCMs. The main advantage is the presence of a fully dynamical and interactive atmosphere, which can mediate air-sea fluxes without the need for artificial restorings or applied forcings, and the possibility of performing millennia integrations in a variety of parameter spaces. Within this configuration we have performed a series of multiple millennial coupled experiments in which we vary some geometrical factor or parameter in order to study the difference in the resulting climate, both its steady-state and variability. These experiments are listed in Table 3.

The constant vertical diffusivity in the ocean is set to $\kappa_{v}=0.5 \times 10^{-4} \mathrm{~m}^{2} \mathrm{~s}^{-1}$. This value is somewhat larger than that observed in the main thermocline but smaller values of diffusivity led to a meridional overturning circulation that was weaker than observed (see Fig. 7, but read below for a discussion on this), possibly because the real thermohaline circulation depends on locally large values of diffusivity (for example over rough topography, and in coastal margins e.g., Samelson, 1998). Moreover, to test the role of vertical diffusivity in our model and its sensitivity, we performed several experiments where $\kappa_{v}$ is modified towards both higher and lower values (for a review on the subject see Kuhlbrodt et al. (2007)). The isopycnal or Redi diffusivity $\left(\kappa_{i}\right)$ and isopycnal thickness diffusivity $\left(\kappa_{t}\right.$, skew-flux advection of tracers by eddies) are both set to $0.8 \times 10^{3} \mathrm{~m}^{2} \mathrm{~s}^{-1}$ in the ocean interior. (In a twin experiment, the use of Laplacian diffusivity instead of the GM parameterisation resulted in qualitatively comparable results.) Constant horizontal, $v_{h}$, and vertical, $v_{v}$, mo- 


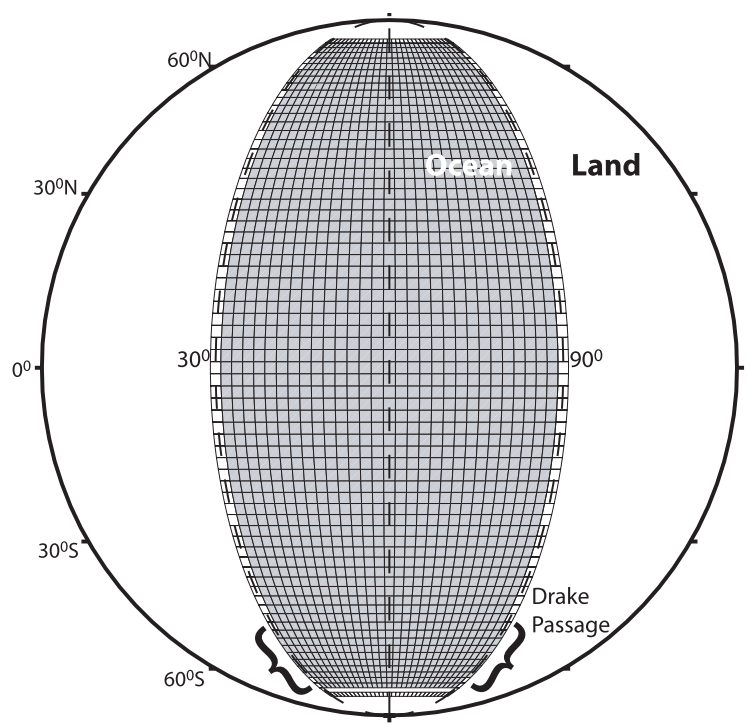

Fig. 1. The oceanic and atmospheric grid in the Atlantic experiment: the ocean basin sits in the centre of the atmospheric sector, spanning $60^{\circ}$ in longitude and from $70^{\circ} \mathrm{S}$ to $70^{\circ} \mathrm{N}$. A cyclic channel extends from $65^{\circ} \mathrm{S}$ to $51^{\circ} \mathrm{S}$. The atmosphere is $120^{\circ}$ wide with solid meridional walls at $84^{\circ} \mathrm{S}$ and $84^{\circ} \mathrm{N}$.

mentum viscosities are set to $1 \times 10^{5}$ and $1 \times 10^{-3} \mathrm{~m}^{2} \mathrm{~s}^{-1}$, respectively. These are somewhat higher than might be ideal, but are necessary in low resolution models to smooth out unphysical noise (Fanning and Weaver, 1997). See Table 1 for a complete list of oceanic parameters. For the Atlantic case, we configure the model into a single ocean basin of similar dimensions to the Atlantic Ocean, with a re-entrant southern channel near the southern boundary representing the Antarctic Circumpolar Current. In Fig. 1, the ocean domain is filled by the grey area together with its actual grid. The ocean domain is $60^{\circ}$ wide and has a latitudinal extension from $70^{\circ} \mathrm{S}$ to $70^{\circ} \mathrm{N}$. The horizontal resolution is constant and has a nominal value of $2.0^{\circ}$; the vertical discretization consists of 24 levels of increasing thickness towards the bottom, which has a depth of $4000 \mathrm{~m}$ and is flat throughout the domain, except in the model Drake Passage, which is $14^{\circ}$ wide between $65^{\circ} \mathrm{S}$ and $51^{\circ} \mathrm{S}$ and has a reduced depth of $2500 \mathrm{~m}$. No-slip conditions at the lateral walls and a drag at the bottom are enforced for horizontal velocities. Cyclic boundary conditions exist in the open channel area.

Since our aim is to study ocean-atmosphere interactions at the basin scale on interannual to centennial time scales, the atmospheric model was configured to run as a zonally reentrant sector with solid meridional walls. Hence, we have excluded possible inter-basin teleconnections. The resulting geometrical configuration is that of a spherical sector model with no poles. The sector atmospheric $\mathrm{B}$-grid is periodic and $120^{\circ}$ wide. Like the ocean component, it has full spherical geometry and the same radius as the Earth and was coupled
Table 3. Different configurations tested for the sector Atlantic simulation. For each experiment, we state in the column "Specifications" only the differences with the Control experiment CTL. (Kv: vertical diffusivity $\left(\mathrm{m}^{2} \mathrm{~s}^{-1}\right)$; GM: Gent-McWilliams; HD: Horizontal Diffusion; DP: Drake Passage; NDP: no Drake Passage.)

\begin{tabular}{lrl}
\hline Name & Yrs & Specifications \\
\hline Kv005 & 1000 & $\mathrm{Kv}=0.05 \mathrm{e}-4$ \\
Kv01 & 1000 & $\mathrm{Kv}=0.1 \mathrm{e}-4$ \\
Kv025 & 500 & $\mathrm{Kv}=0.25 \mathrm{e}-4$ \\
Kv05 (CTL) & 2000 & $\mathrm{Kv}=0.5 \mathrm{e}-4$; GM, DP \\
Kv1 & 500 & $\mathrm{Kv}=1.0 \mathrm{e}-4$ \\
Kv2 & 500 & $\mathrm{Kv}=2.0 \mathrm{e}-4$ \\
Kv5 & 500 & $\mathrm{Kv}=5.0 \mathrm{e}-4$ \\
X2 & 1000 & $2 \times$ wide Ocean \\
NDP & 1000 & no Drake Passage \\
HD & 1000 & Laplacian Diffusivity \\
NoWall & 500 & No meridional walls \\
\hline
\end{tabular}

to the ocean and land components through the GFDL FMS exchange grid. The resolution is equivalent to the GFDL M30, corresponding to a nominal horizontal resolution of $3.75^{\circ} \times 3^{\circ}$, and 7 uneven levels in the vertical.

The geometrical effects have been studied with four major modifications: the closing of the Drake Passage (NDP), the widening of the oceanic basin (X2), shallowing the basin depth $(\mathrm{H})$ and the removal of the zonal walls rendering the ocean basin a re-entrant channel (NoWall). The oceanic parameters that have been explored are the vertical diffusivity $\kappa_{v}$ and the parameterisation of horizontal diffusivity (Gent and McWilliams (GM) vs. Laplacian horizontal diffusivity (HD)). Here we mainly restrict our attention to the Control (CTL) solutions, as the main focus of the present paper is on the description of a base integration. Furthermore, we tested the climatic response to variations of some fundamental parameters of the climate system such as the moisture content in the atmosphere, the meridional gradient of the incident solar flux and the Earth's rotation rate. Various numerical experiments and analyses on the climate variability, energy transport in the coupled system and their dependence on oceanic, atmospheric and planetary parameters and dimensions will be presented elsewhere. The archived data files and analyses from all of the above mentioned sensitivity integrations can be made available to the interested reader.

\section{Coupling procedure}

The different model components are run simultaneously from their initial conditions. The ocean-ice and atmospheric modules have a $3 \mathrm{~h}$ and $1 \mathrm{~h}$ time step respectively, while direct coupling occurs daily without any flux adjustment. Time steps, both in the ocean and atmosphere, are functions of resolution and physical packages, and thus may vary accordingly to the experimental set-up. The surface fluxes of heat, 


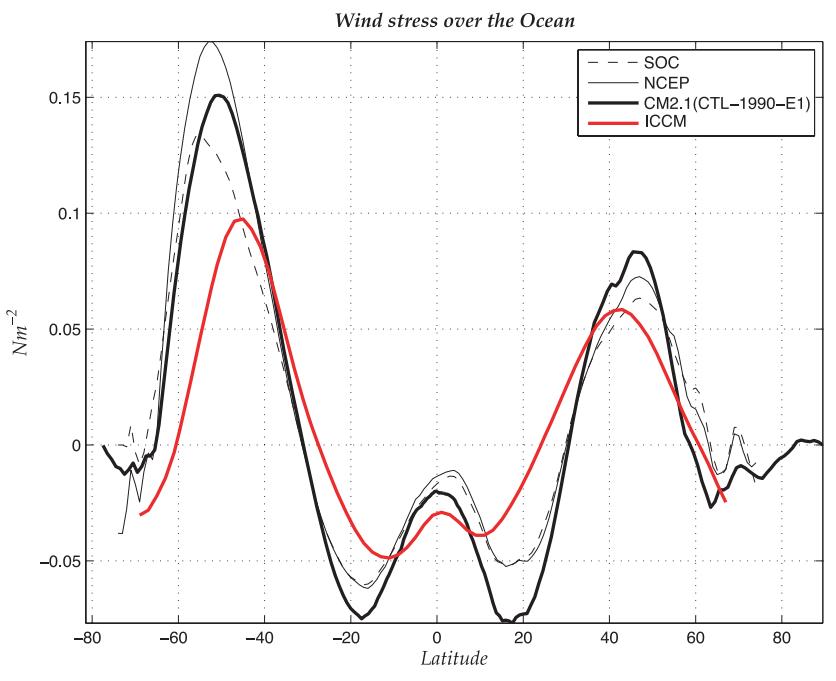

Fig. 2. The wind stress over the ocean for the ICCMp1 model (red line, Atlantic case) and the GFDL CM2.1 (heavy black line). The other two curves are observational data sets. The major deficiencies are a too small difference between the Northern and Southern Hemisphere midlatitude jets, and the equatorward position of the Soutehern midlatitude jet.

moisture and momentum are plotted in Figs. 2 and 3, and a list of the main parameters is given in Table 1. The IC$\mathrm{CMp} 1$ momentum, heat and freshwater fluxes compare reasonably well with those generated by the present-day GFDL CM2.1 simulation and some reanalysis datasets over the Atlantic region (Figs. 2 and 3). The main deviation is found in the momentum flux, which is too weak and equatorwards in the Southern Hemisphere, although this has been a long standing problem for many atmospheric models in the past.

With the Atlantic configuration and resolution, the atmosphere, although highly idealised, takes around 6 times more CPU time than the ocean. Besides being a limitation, this also means that refining the oceanic resolution, or even the addition of a second basin, does not slow down the coupled model integration significantly (as we will see later). Presently, the model is capable of performing 15 model years per wallclock hour on 32 processors.

\subsection{Mean climate}

\subsubsection{The ocean}

The ocean basin resembles the Atlantic ocean in its geometry and we thus find a roughly similar circulation, except in so far as the presence of other ocean basins influence the circulation of the Atlantic.

The time-mean zonal-mean potential temperature and salinity are shown in Fig. 4. Cold and relatively fresh waters are subducted in the Southern Hemisphere close to the reentrant channel mimicking the Drake Passage. A reasonably realistic, albeit overly diffusive, thermocline is maintained
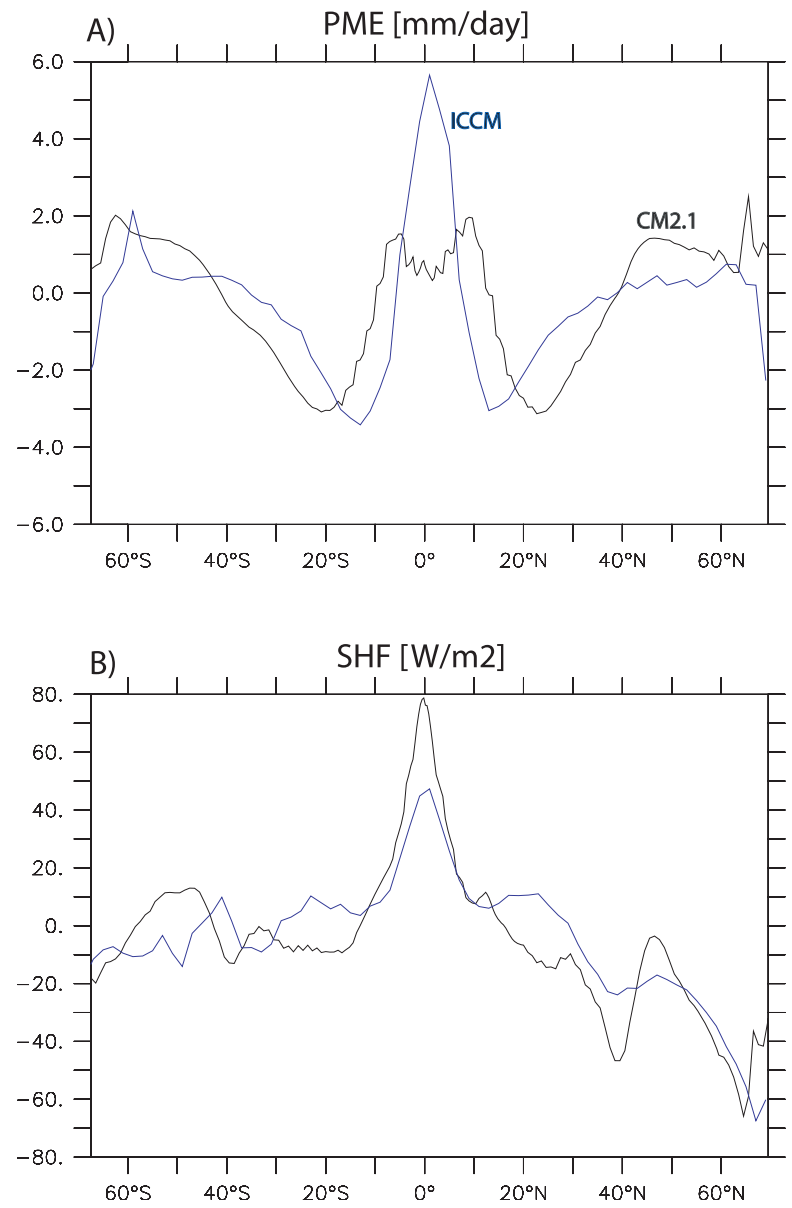

Fig. 3. Precipitation-minus-evaporation (PME, top) and surface total heat flux (SHF, bottom) comparison between the Atlantic ICCMp1 model (blue line) and the CM2.1 (black line) over the Atlantic ocean.
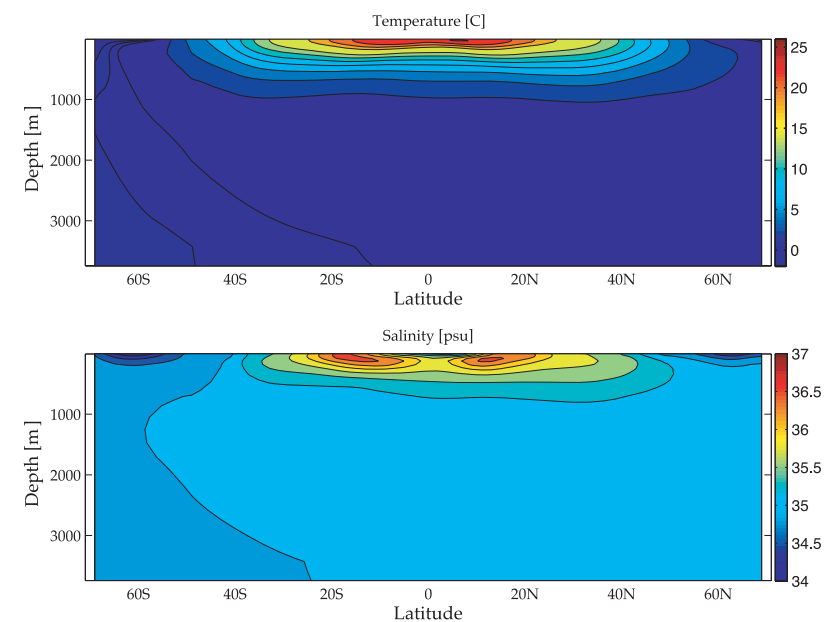

Fig. 4. Zonal mean potential temperature and salinity for the Atlantic Control case in which $\kappa_{v}$ is set to $0.5 \times 10^{-4}\left[\mathrm{~m}^{2} \mathrm{~s}^{-1}\right]$. Maximum surface temperature and salinity reach $26^{\circ} \mathrm{C}$ and $36 \mathrm{psu}$, respectively. In the South, cold fresh water flows downward and towards the centre of the basin reminiscent of the AABW; however, the model does not create an Atlantic Intermediate water tongue. 

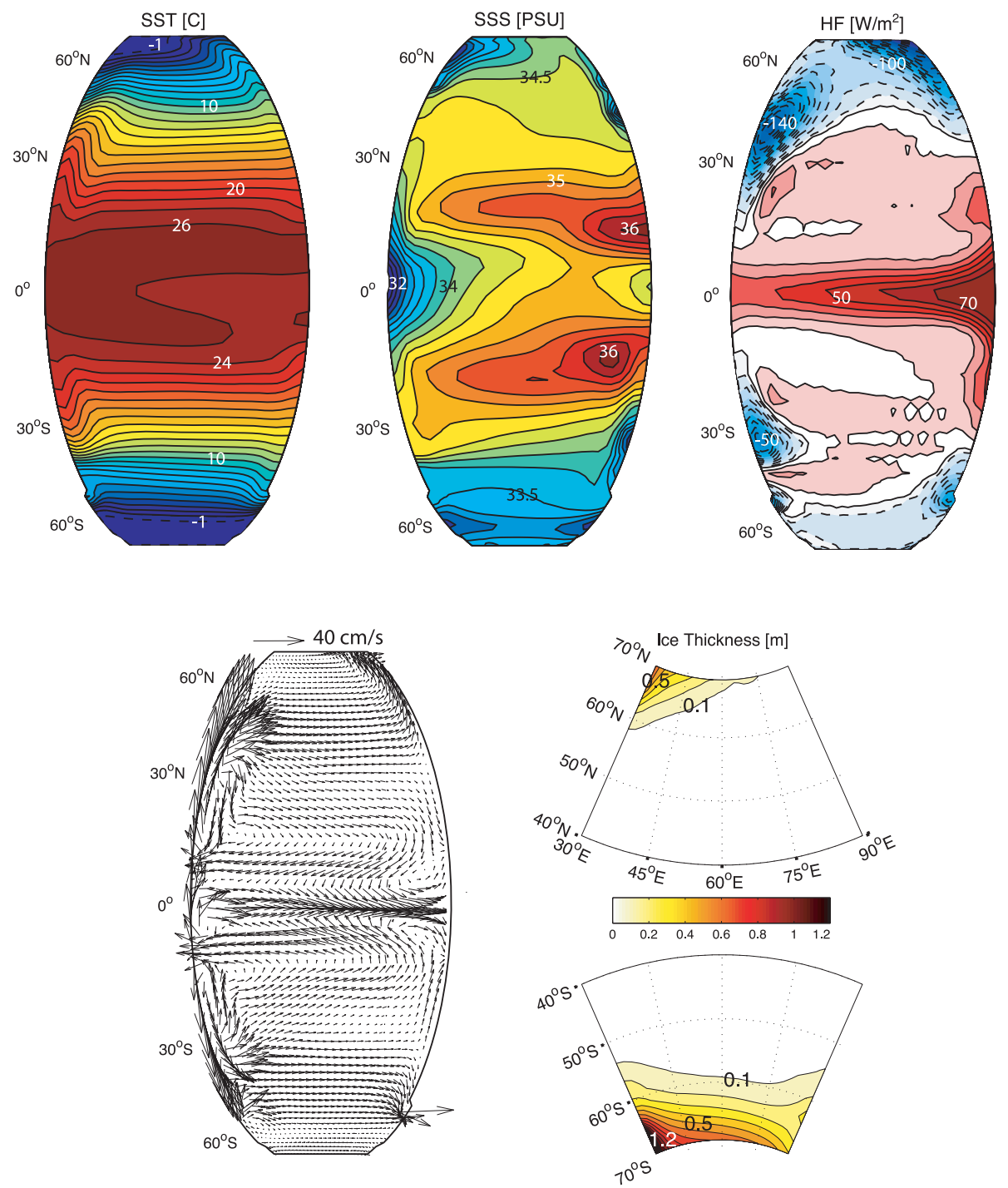

Fig. 5. Sea surface temperature (SST), salinity (SSS), heat flux (HF), 100-m-averaged mean oceanic currents and sea-ice thickness in the Atlantic experiment. The contour interval is $1^{\circ} \mathrm{C}$ for temperature, $0.25 \mathrm{psu}$ for salinity and $10 \mathrm{~W} \mathrm{~m}^{-2}$ for the surface heat flux and $0.1 \mathrm{~m}$ for sea-ice; a reference velocity arrow is given at the top of the fourth panel for velocity reference.

and subtropical maxima in salinity are present. Experiments with different values of $\kappa_{v}$ vary substantially in their depth of the thermocline and abyssal stratification, with CTL being the closest to real Atlantic conditions.

Many aspects of the mean state oceanic conditions can be interpreted from the panels of Fig. 5: an equatorial cold tongue is present, sea-ice concentration is asymmetric between the poles, surface salinity has two major salty limbs in the subtropics and region of freshwater river discharge are visible. Finally the ocean gains heat in the equatorial region (positive flux is into the ocean) and loses heat to the atmosphere at the poles and in the western boundary current areas. The surface circulation presents a subtropical and a subpolar gyre in the Northern Hemisphere while only a subtropical gyre exists in the Southern Hemisphere due to the presence of a strong re-entrant flow in the area of the Drake Passage. Velocities at mid-depth reveal a north-eastward flow converging towards the northern boundary. Here the advected water loses heat to the atmosphere and deep convection takes place. Finally, the deep-water formed at high latitudes recirculates westward and equatorward via a deep western boundary current visible at greater depths (Fig. 6). The presence of an Antarctic Circumpolar Current also affects the presence of sea-ice in the model, with asymmetrical conditions in the ice concentration resulting in a higher area coverage in the Southern Hemisphere. Here, deep water formation occurs in an analogy of the Antarctic Bottom Water (AABW) generating a cell confined to the southern boundary and an abyssal anti-clockwise branch of the MOC reaches the northern subtropics peaking at about $5 \mathrm{~Sv}\left(1 \mathrm{~Sv} \equiv 10^{9} \mathrm{~kg} \mathrm{~s}^{-1}\right.$ 

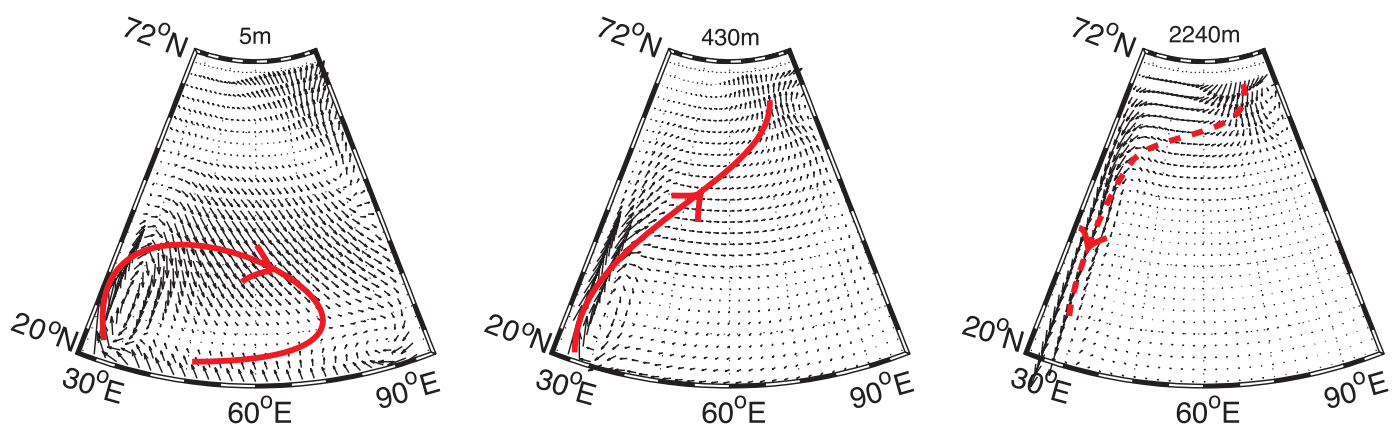

Fig. 6. Surface, mid-depth and deep horizontal circulation. The red arrows are schematics of the main circulation patterns at different depths: a strong subtropical gyre at the surface; then a western boundary current and northeastward flow at $400 \mathrm{~m}$ converging in the northeastern corner of the basin where it is associated with deep convection; and finally, at $2000 \mathrm{~m}$, a southward deep western boundary current and divergent flow in the northeastern boundary.
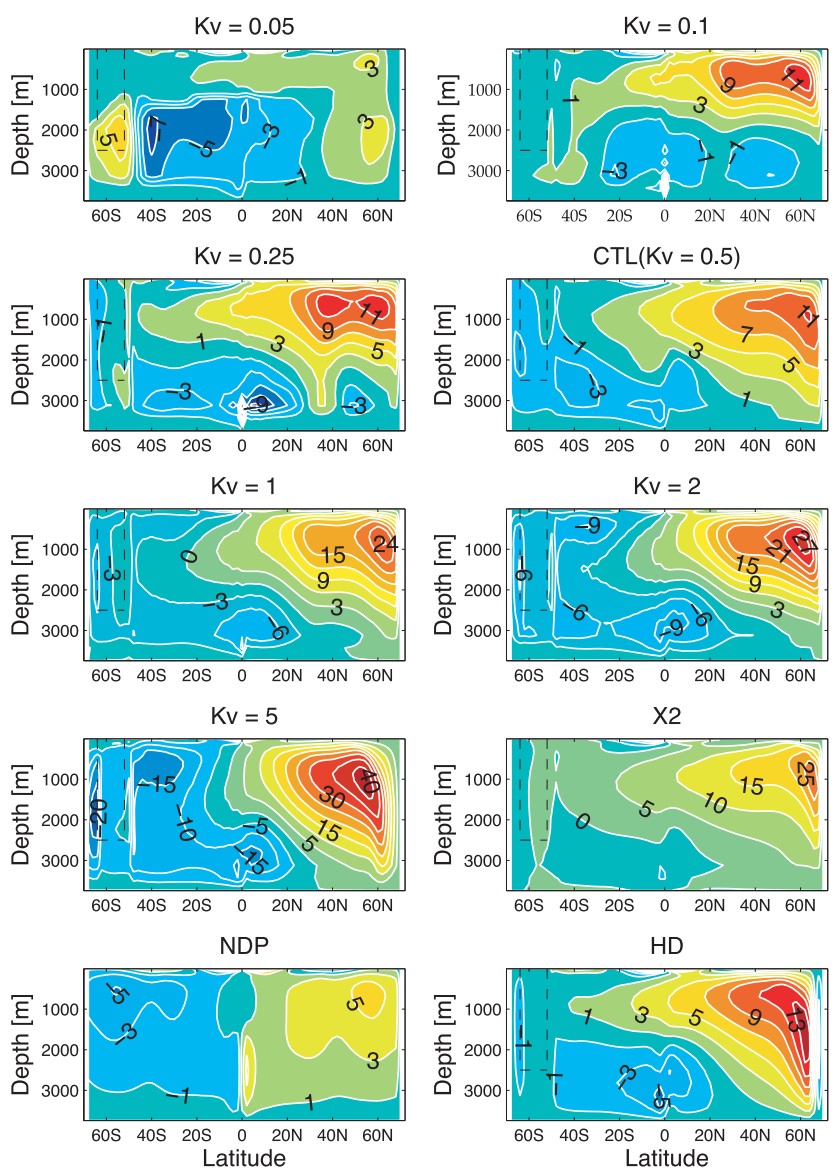

Fig. 7. The time-mean residual meridional overturning circulation in Sverdrups $\left(\mathrm{Sv} \equiv 10^{6} \mathrm{~m}^{3} / \mathrm{s}\right)$ in the different coupled experiments for different values of vertical diffusivity $\left(\mathrm{Kv}\right.$, in $\left.\times 10^{-4} \mathrm{~m}^{2} \mathrm{~s}^{-1}\right)$, basin width (X2, two times wider), no Drake Passage (NDP, closed basin) and Laplacian horizontal diffusivity (HD, same parameter value as in GM). of mass transport) for the CTL case. This is shown in Fig. 7 where the time mean residual meridional overturning circulation (MOC) is shown in physical space for some of the coupled experiments. In the Northern Hemisphere, both buoyancy forcing and mechanical energy produce a reasonably realistic overturning circulation of $\sim 12 \mathrm{~Sv}$ extending to a depth of $2500 \mathrm{~m}$.

Figure 7 also clearly shows the dependency of the MOC on the background vertical diffusivity, both in its spatial structure and magnitude. The northern branch is vanishing for lower values of $\kappa_{v}$, while a more symmetrical circulation develops with increasing vertical diffusivity due to a stronger southern cell. The wind-driven asymmetry generated by the opening of the Drake passage will eventually become of second order importance in a diffusively-dominated circulation. Shallow tropical wind-driven cells disappear for sufficiently strong values of $\kappa_{v}$. As expected, with the closure of the Drake passage the circulation becomes symmetric around the equator.

The total time mean energy transport in the ocean is approximated by

$\Phi^{o} \approx \rho_{o} C_{p}^{o} \int v \theta \mathrm{d} x \mathrm{~d} z$,

where $\rho_{o} C_{p}^{o}$ is the volumetric specific heat of the ocean, $v$ the meridional velocity and $\theta$ the potential temperature.

Following earlier studies (e.g. Fanning and Weaver, 1997; Kamenkovich et al., 2000a), the stationary total oceanic meridional energy transport can be decomposed into an overturning and gyre component. Denoting a zonal average by $[\mu]$ and the deviation from it with an asterisk $\mu^{*}$, we get: 

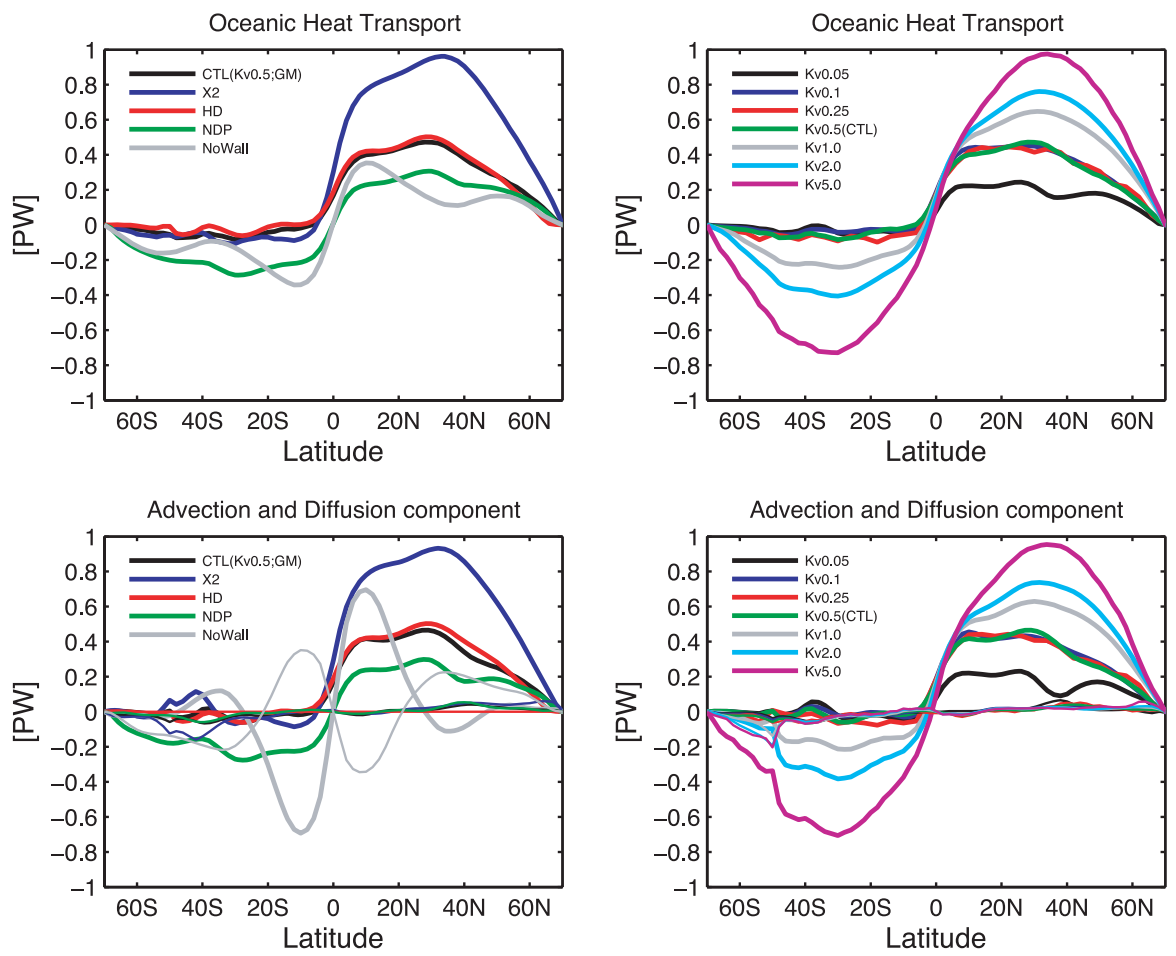

Fig. 8. Meridional oceanic heat transport for all different experiments. Top: total transport including neutral physics. Bottom: advection (heavy lines) and diffusive (light lines) components.

$$
\begin{aligned}
\rho_{o} C_{p}^{o} L \int_{-H}^{\eta}[v \theta] \mathrm{d} z & =\underbrace{\rho_{o} C_{p}^{o} L \int_{-H}^{\eta}[v][\theta] \mathrm{d} z}_{\text {overturning }} \\
& +\underbrace{\rho_{o} C_{p}^{o} L \int_{-H}^{\eta}\left[v^{*} \theta^{*}\right] \mathrm{d} z}_{\text {gyre }},
\end{aligned}
$$

where $L$ is the width of the basin, $H$ its total depth and $\eta$ the surface elevation.

A qualitative crude comparison of the energy transports in the model and observations will be given later on (see Sect. 3.1.2); here we focus on the oceanic component and its dependency on different parameters. The oceanic energy transport and its decomposition into advective and diffusive parts, as well as the overturning and gyre contributions are shown in Figs. 8 and 9, respectively. In experiments where $\kappa_{v}$ is varied (right panels of Fig. 8) we clearly see that the more diffusive the ocean, the more symmetric around the equator the heat flux becomes, consistent with the overturning circulation behaviour. Also, the diffusive transport (thin lines in the bottom panels of Fig. 8) plays a negligible role in all simulations except in the vicinity of the Drake passage,

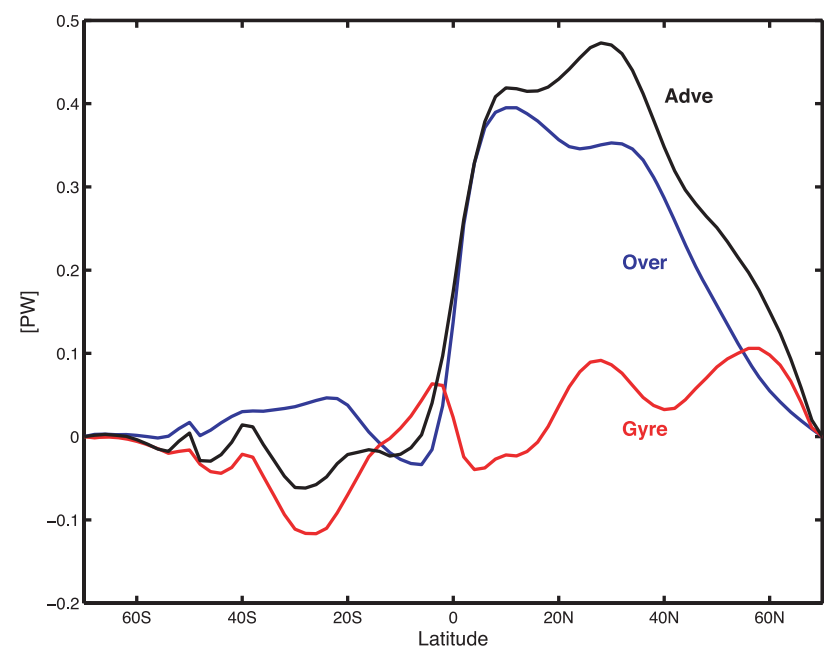

Fig. 9. Meridional oceanic heat transport for the Control (CTL) case $\left(\kappa_{v}=0.5 \times 10^{-4}\right)$. Advection (black), Overturning (blue) and Gyre (red) component.

where it has an indirect effect by flattening the isopycnals. In the NoWall experiment (where the meridional walls are removed and replaced with zonally cyclic conditions) the classical gyre circulation, with a Sverdrup interior and western boundary currents, is completely removed. The meridional 

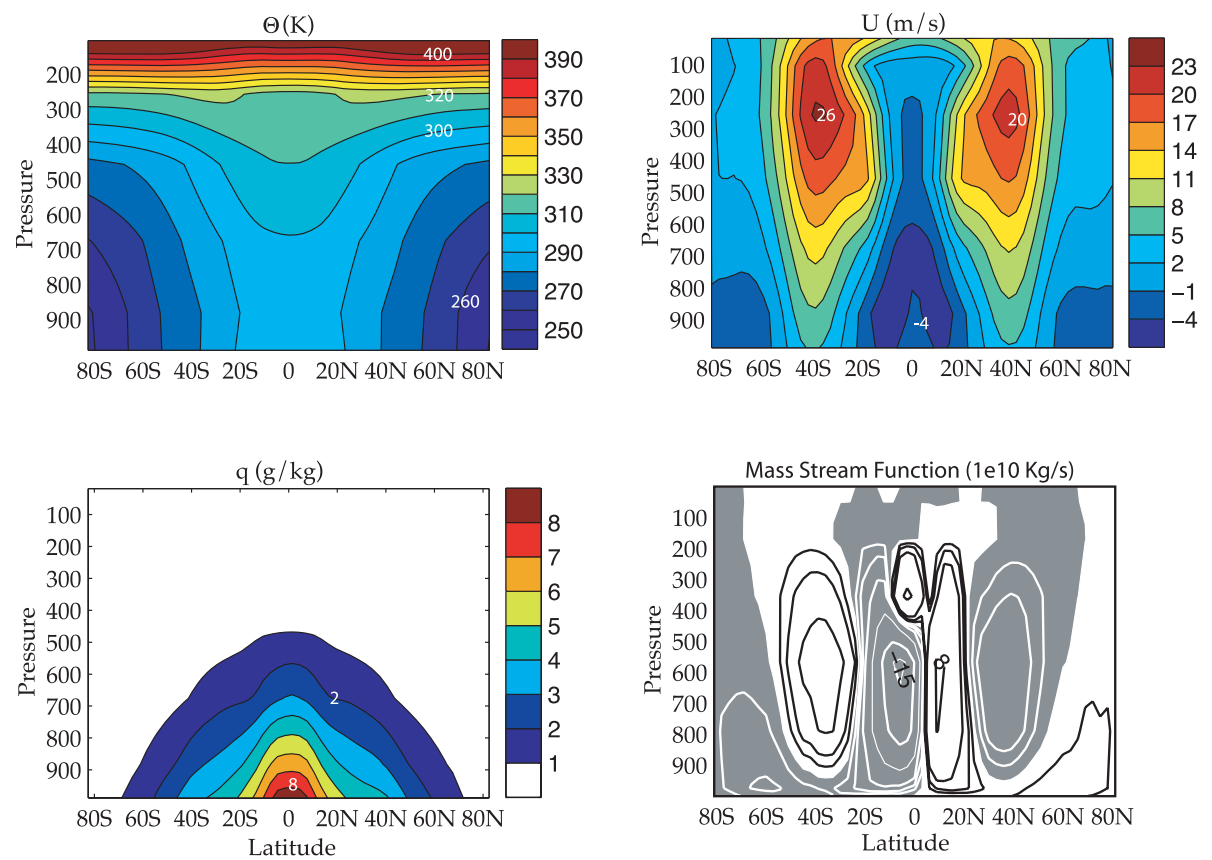

Fig. 10. Zonal mean atmospheric potential temperature $\Theta$, zonal wind $U$, humidity $q$ and mass streamfunction $\psi_{a}$ in the sector atmosphere. The jet is stronger in the Southern Hemisphere and projects onto stronger surface westerlies; the southern Hadley cell is also stronger and penetrates across the equator. From the depth of the Ferrel cells we can see that the planetary boundary layer is very deep due to relative too warm land over half of the domain. Note that there is no seasonal cycle in the model.

heat transfer is driven by the deep overturning circulation, the Ekman transport and associated shallow cell at low latitudes, and by mesoscale eddies, which are parameterised in our integrations. While in the CTL case the mesoscale eddy parameterisation (the GM term) makes almost no direct contribution to the energy transport, in the case with no meridional walls the isopycnals are almost vertical and the GM contribution is large, consistent with the results of Marshall et al. (2007) (see also later for our Aquaworld configuration).

Finally, for all experiments the meridional energy transport is dominated by the overturning component (Fig. 9), while the gyre component is significant only at high latitudes or in the Southern Hemisphere, where the heat flux is relatively small.

\subsubsection{The atmosphere}

As we have noted in Sect. 2, the main simplifications in the ocean model are geometrical while the atmospheric component has important idealisations and omissions in its physical processes, and we therefore might expect a greater deviation from the climatology of a state-of-the-art atmospheric model. Nonetheless, we do find a qualitatively and, in some aspects, quantitatively realistic atmospheric circulation.

The zonal mean atmosphere is summarised in Fig. 10 where potential temperature, zonal winds, humidity and mass stream function are plotted. The model exhibits a fairly realistic pattern from low to high latitudes with somewhat weak hemispheric asymmetry, with stronger surface westerlies and lower values of humidity in the Southern Hemisphere due to more sea-ice there. The westerly jets at mid-latitudes are the regions of maxima in the eddy kinetic energy corresponding to our "storm tracks" and downstream eddy momentum fluxes (see Fig. 12). The atmospheric circulation possesses a Hadley cell with a maximum mass transport of $150 \mathrm{~Sv}$, weaker Ferrel cells of about $20 \mathrm{~Sv}$ and some poorly resolved polar cells.

Because the atmospheric sector is a third of the Earth and the ocean only has one basin of Atlantic dimensions we expect the magnitude of the energy transport in both fluids to be different accordingly. In Fig. 11 we look at the mean meridional energy transports in the model and find that the planetary heat transport (PHT) is close to a third of the lower bound found in reanalyses estimates (Trenberth and Caron, 2001); the partition between the atmospheric (AHT) and oceanic (OHT) heat transports also follows the previous relationship and the small basin has to carry the burden of all poleward oceanic heat transport. Unlike the coarse ocean where mesoscale eddies are parameterised, the atmosphere resolves the baroclinic eddies that drive most of the energy transfer. The time-mean zonally averaged energy transport in the atmosphere is given by 
$\Phi^{a}=\int\left(C_{p}^{a} T+g z+L q\right) v / g \mathrm{dpd} x$

where $v$ is the meridional component of the total velocity, $C_{p}^{a}$ is the specific heat capacity of the atmosphere, $T$ its temperature, $g z$ the geopotential height, $L$ is the latent heat of condensation and $q$ is the specific humidity. From Fig. 11 we see how the dry static energy ( $\left.\mathrm{DSE}=C_{p} \mathrm{~T}+\mathrm{gz}\right)$ compensates the equatorward latent transport of moisture ( $\mathrm{LE}=L q$ ) in the Hadley cell region and the latitude of maximum total flux (PHT in Fig. 11) is about 37 degrees, consistent with observations (Trenberth and Caron, 2001). A primary deviation from observational estimates is in the ratio between DSE and LE in the present configuration, which is about twice as much as in the observations of Trenberth and Stepaniak (2003), and is mostly due to lower humidity contents over land and the high land fraction throughout the domain.

Overall, with the given differential solar heating, the idealised coupled model is capable of reproducing a fairly realistic climate in both the ocean and atmosphere, given the caveats appropriate for a simplified model. The model's idealisations keep the system simple enough as to highlight the main mechanisms of interaction between the ocean and atmosphere at interannual and longer time scales, but at the same time do not oversimplify to the point of unrealism.

\subsubsection{Sea-ice}

The sea-ice climatology is, as expected, asymmetric around the equator because of the presence of the Drake Passage and the resulting meridional heat flux in the ocean. As in real Atlantic ocean conditions, more sea-ice is generated downstream the Antarctic peninsula (represented here by the wall on the South West corner of the domain) extending all the way to the eastern end of the Atlantic Ocean. In the Northern Hemisphere, sea-ice is concentrated in the North West corner, possibly because of the cold continental air flowing easterly and the effect of the subpolar gyre advecting warm water to the North eastern corner of the ocean basin (Fig. 5, right panel).

\section{The Aquaworld configuration}

The ICCMp1 is not restricted to a sector configuration, and the natural generalization is that of a "full-Earth" geometry (called here Aquaworld), where a spherical atmosphere is exchanging freshwater, heat and momentum fluxes with an Earth that is totally covered by water with the only exception of two polar caps that are necessary for the sea-ice model. The coupled model now resembles the configurations of Smith et al. (2006) and Marshall et al. (2007), the only other modelling initiatives where a dynamical atmosphere is coupled to a dynamic ocean with no continents. With respect
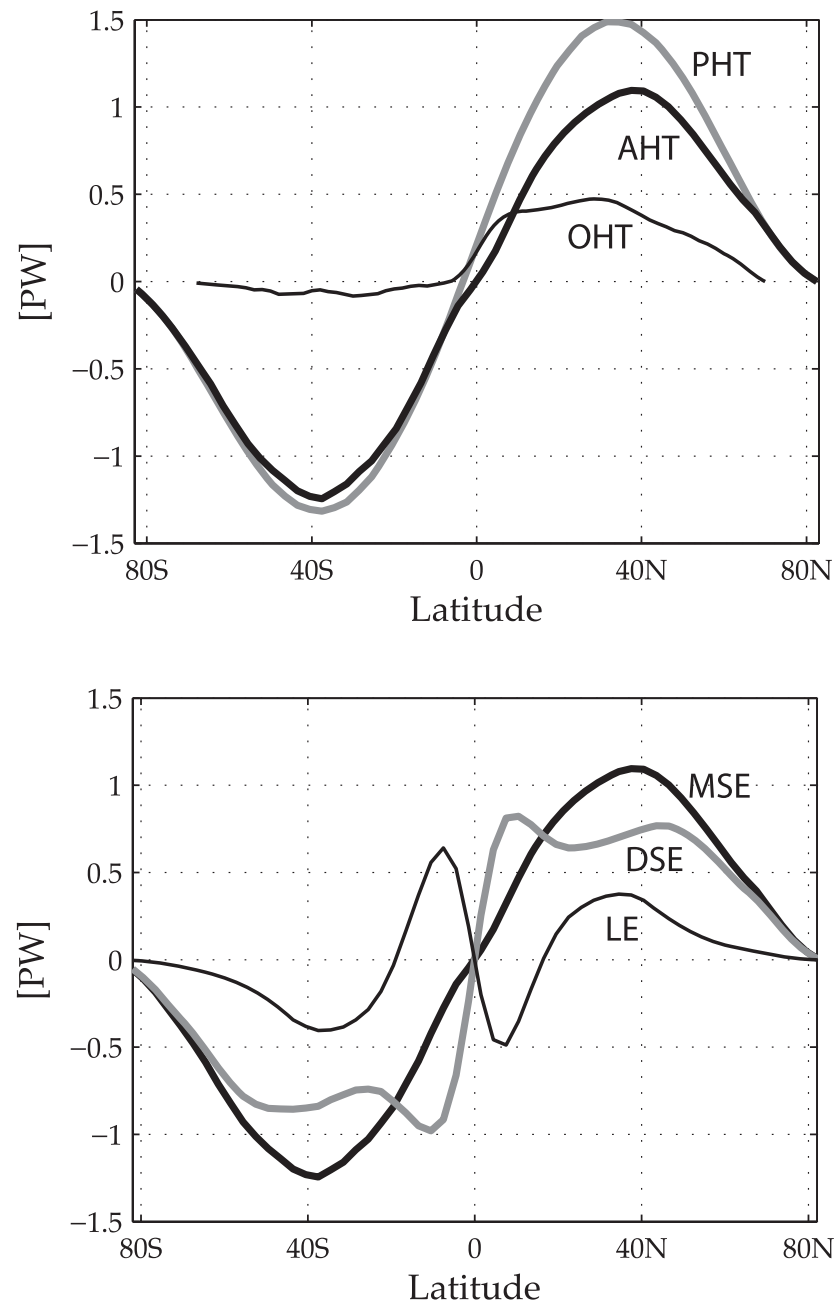

Fig. 11. Top panel: planetary (PHT), atmospheric (AHT) and oceanic (OHT) heat transport for the sector Atlantic model. Lower panel: AHT or moist static energy $\left(\mathrm{MSE}=C_{p} T+g z+L_{v} q\right)$, dry static energy $\left(\mathrm{DSE}=C_{p} T+g z\right)$ and latent energy $\left(\mathrm{LE}=L_{v} q\right)$ in the CTL simulation.

to the Atlantic experiment, only geometrical differences exist in the case of the Aquaworld model, and all other parameters and model characteristics have remained constant. Also, the model is now roughly only three times slower, as most of the CPU time is taken up by the atmosphere.

A flavour of the Aquaworld climate a few centuries into the spin-up phase is shown in Figs. 13-16. We can identify a strong equatorial upwelling in the ocean, giving rise to a global temperature cold tongue as well as saline mid-latitude tongues (Fig. 13). Polar temperatures are very cold and seaice reaches down to about $60^{\circ}$ in latitude (Fig. 14). The zonal winds drive strong zonal currents in the ocean that are ultimately dissipated by bottom stress. Although the model is not fully spun-up there is no indication of a deep meridional circulation at the poles. In the absence of meridional walls, the zonally averaged zonal pressure gradient is zero and there 

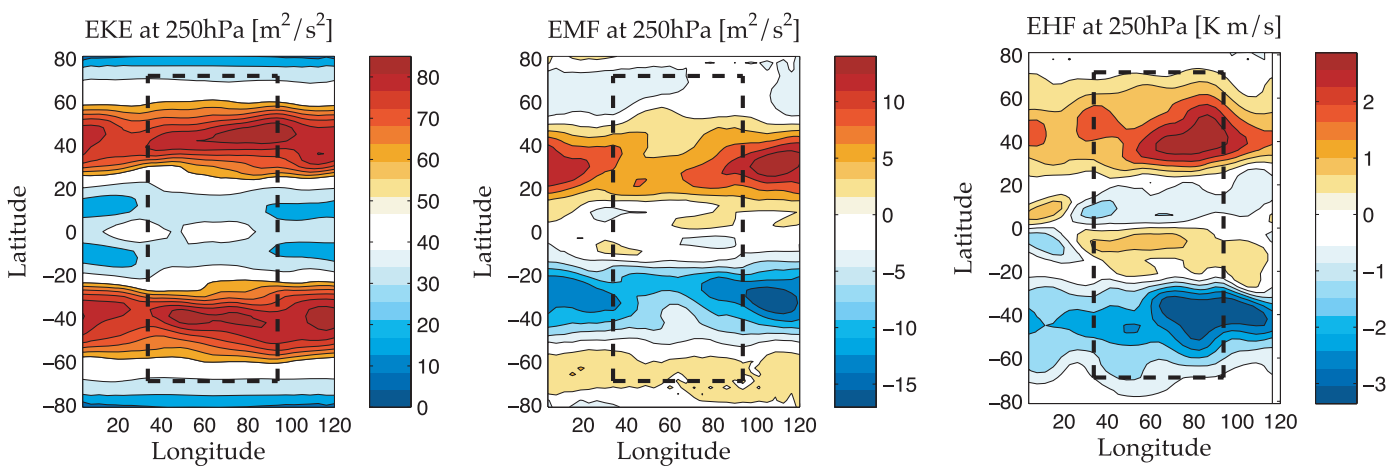

Fig. 12. Eddy Kinetic Energy (EKE), Eddy momentum flux (EMF) and Eddy heat flux (EHF) at 250 hPa for the Atlantic CTL experiment. The dotted squared box represents the ocean basin.
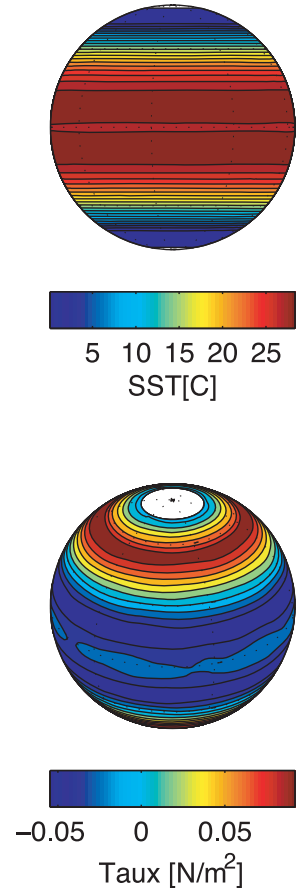
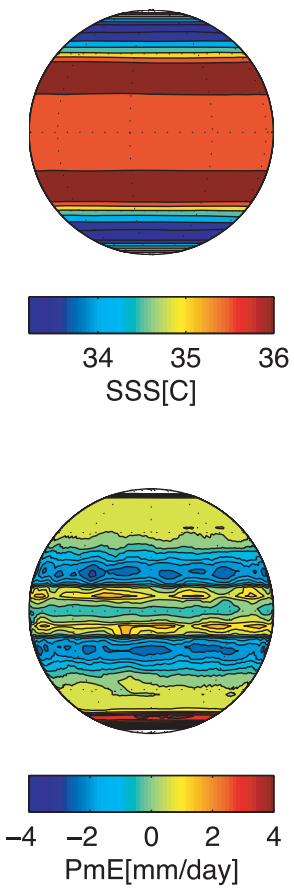
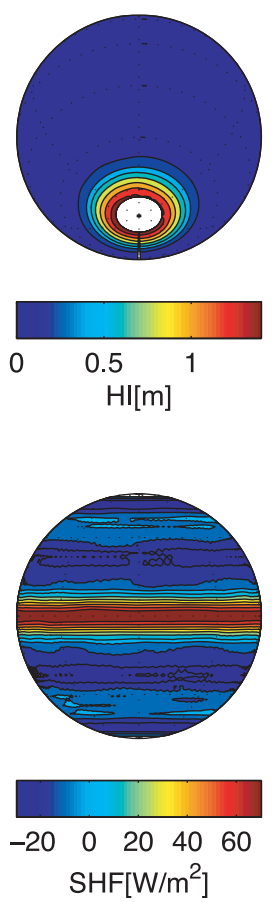

Fig. 13. Some oceanic fields during spin-up of the Aquaworld experiment. From top left: sea surface temperature (SST), sea surface salinity (SSS), sea-ice thickness (HI) in meters, zonal wind stress (Taux) in $\mathrm{N} \mathrm{m}^{-2}$, precipitation minus evaporation (PmE) in mm day ${ }^{-1}$ and the total surface heat flux (SHF) in $\mathrm{W} \mathrm{m}^{-2}$. The polar islands can be seen in some of the plots.

can be no zonally-averaged geostrophic flow in the interior. Any net meridional Ekman transport at the surface cannot be returned in the ocean interior and all the cells return in a bottom boundary layer; hence, there is no hemisphericscale meridional overturning circulation in the ocean (not shown). Whilst the oceanic resolution is too coarse to resolve the small oceanic Rossby radii (hence mesoscale processes have to be parameterised) the radius of deformation in the atmosphere is much larger and so synoptic scale systems arise naturally. To demonstrate this, some daily snapshots are given in Fig. 15, where rich structures are clearly visible, especially in the mid-latitudes. How the meridional energy transport is partitioned between the two fluids in the Aquaworld model is illustrated in Fig. 16. Basic features are the symmetry of the transport around the equator, the larger transport accomplished by the ocean at very low latitudes and the dominance of the atmosphere at mid and high latitudes. As in the Atlantic experiment with no meridional walls (NoWall), the eddy-induced (bolus) transport opposes the eulerian transport giving rise to a total transport that is polewards at all latitudes.

The similarities with the Earth's present climate are evident, in both magnitude and patterns, and this was also noted by Enderton and Marshall (2009) with similar exper- 

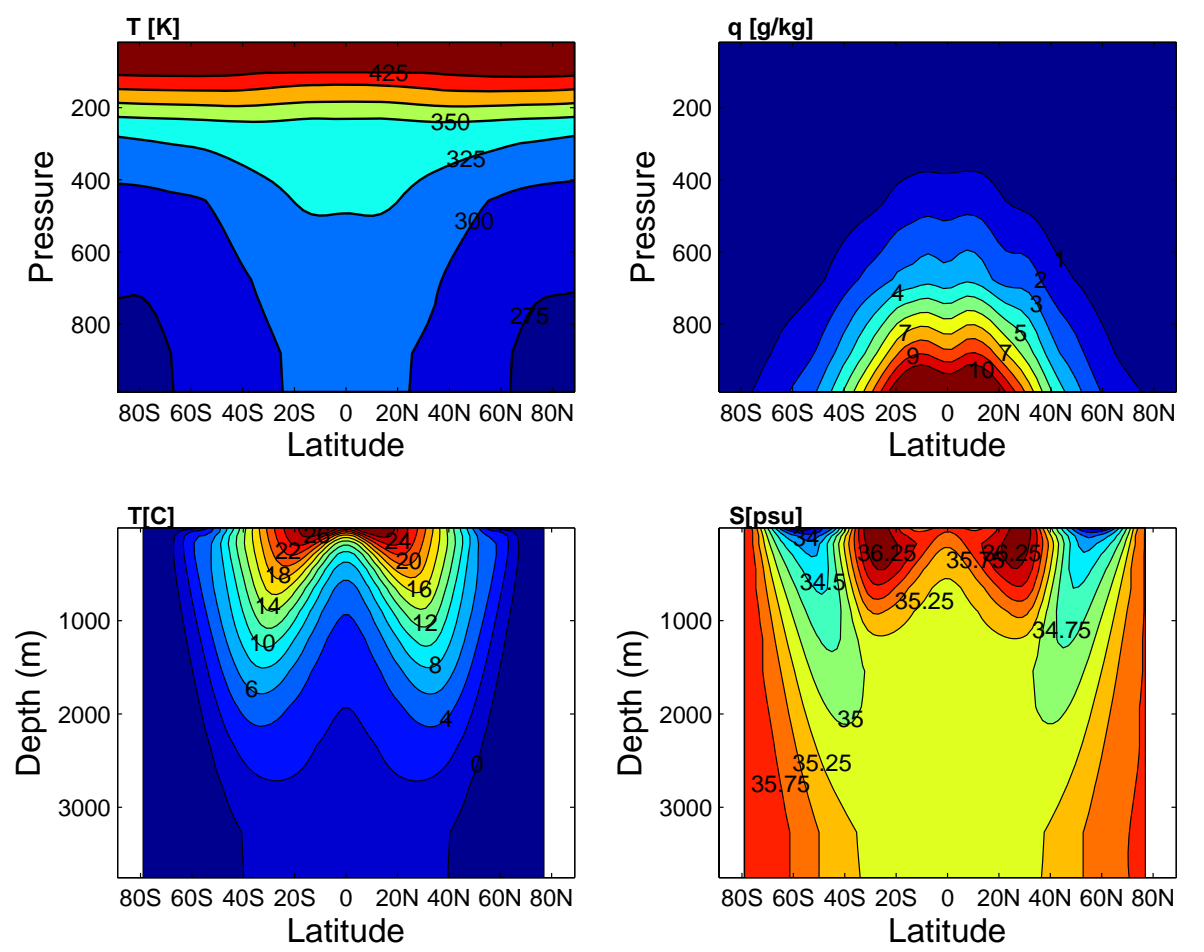

Fig. 14. Zonal mean atmospheric and oceanic structure during spin-up of the Aquaworld experiment. In the top panels are the atmospheric potential temperature $\left(\mathrm{CI}=25^{\circ} \mathrm{K}\right)$ and relative humidity $(\mathrm{CI}=1 \mathrm{~g} / \mathrm{Kg})$ while the bottom panels show the oceanic potential temperature $\left(\mathrm{CI}=2^{\circ} \mathrm{C}\right)$ and salinity $(\mathrm{CI}=0.5 \mathrm{psu})$.

iments. Hence the Aquaworld model is a useful tool for studies of the partition and sensitivity of the heat transport in both the atmosphere and ocean subject to different perturbations. The model is totally flexible to changes in its basic geometrical configuration and sets of parameters and parameterisations; the two experiments presented in this paper should be regarded as mere examples of many possible configurations. For example, the ocean circulation can be restricted by the incorporation of one or more walls that would block the flow and set-up a gyre circulation and western boundary currents, giving rise to many different climatic responses. Although these experiments might seem extremely idealised, they not only give much insight into the dynamics of ocean-atmosphere interactions for the climate of the Earth in present day conditions (Marshall et al., 2007) but also serve as a useful test for paleoclimate circulations, biogeochemical processes and dependencies on geometrical factors on both circulations and air-sea exchanges. Some of these ideas are presently been applied to the model with a suite of Aquaworld configurations.

\section{Summary and discussion}

In this paper we have described the ICCMp1, an intermediate complexity climate model based on the GFDL FMS. Com- pared to a full CGCM the model is idealised and fast, but it is nevertheless based on the full, three-dimensional primitive equations of motion in both fluids. The model's principal simplifications come from its geometry and its austere atmospheric physical parameterisations. The ICCMp1 model is able to perform multiple millennial integrations, making a parameter study feasible at those periods. The idealised atmospheric physics based on the work of Frierson (2005) was introduced in a modular way into the GFDL B-grid atmospheric dynamical core, and it is thus possible to recover the state-of-the-art parameterisations with a simple namelist change. Changes in the ocean, sea-ice and land components are either geometrical or make use of the simplest (and computationally efficient) configuration available. The model is now supported within the standard MOM releases as one of its many test cases. Access to the Fortran code is freely available and all input files and archived data can be made available upon request. We expect the coupled model to evolve in time and to be flexible in its possible configurations, depending on the scientific question posed. Several idealised configurations - or even realistic continental geometry - can be set up with such a model and many of them are presently been used to study a variety of processes. Here we presented two principal geometrical configurations: a sector model built to reproduce the Atlantic basin conditions and a water-covered spherical Earth. In the first case, the model was found to 

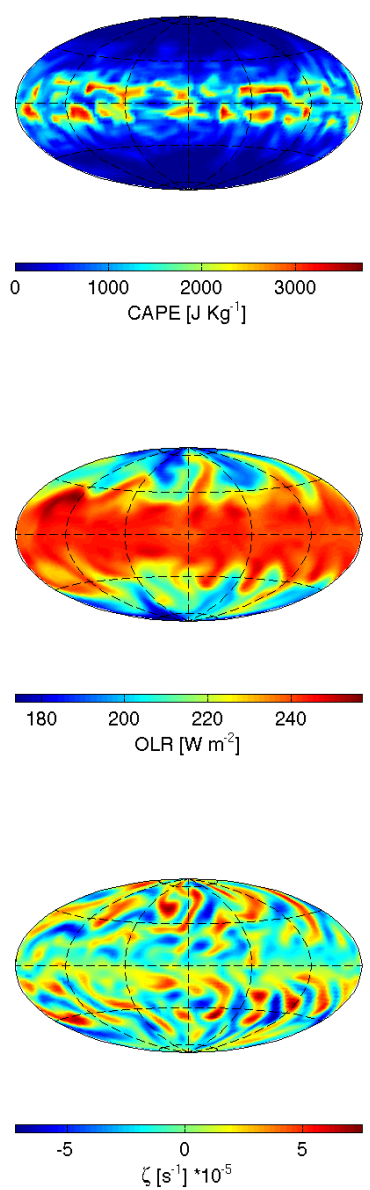
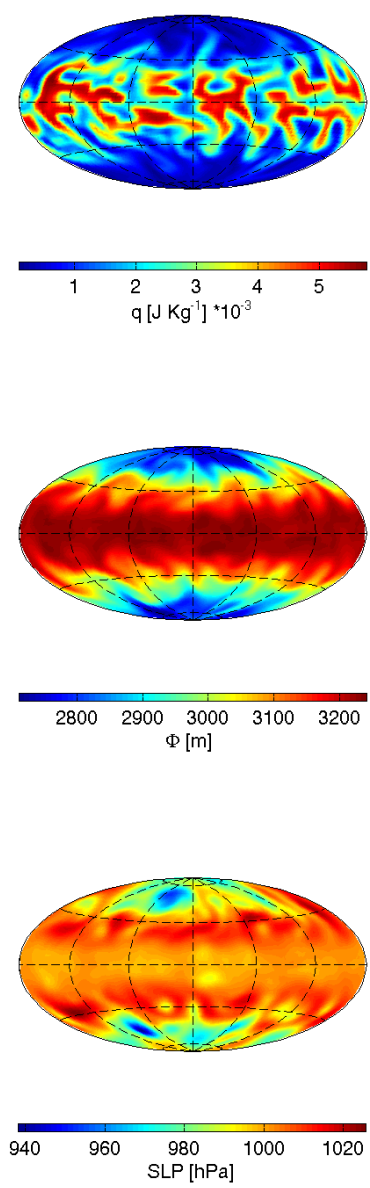

Fig. 15. Daily snapshot of some atmospheric fields for the Aquaworld experiment. From top left: convectively available potential energy (CAPE), specific humidity $(q)$ at $500 \mathrm{mb}$, outgoing longwave radiation (OLR), geopotential height $(\Phi)$ at $500 \mathrm{mb}$, relative vorticity $(\zeta)$ at $500 \mathrm{mb}$ and sea level pressure (SLP).

reproduce a reasonably realistic circulation in both the atmosphere and ocean, with the latter being very similar to an Atlantic-like climate in its control simulation. Sensitivity to a set of parameter values and geometrical settings was also briefly discussed.

One purpose of using such a model is to provide a pathway between reality and theory because GCMs in realistic geometries (which in turn are much less complex than the real ocean-atmosphere system) are generally too complicated to allow straightforward application of many theoretical ideas. The presence of topography and non-regular basin shapes, for example, means that classical ideas from ocean dynamics are hard to apply, and the complications of clouds in the atmosphere make the interpretation of the effects of moisture very difficult. By using simpler models we hope that the connection to theory may be made more directly, yet by using the primitive equations with all the dynamics of climate models we avoid the oversimplications of still more idealiza-
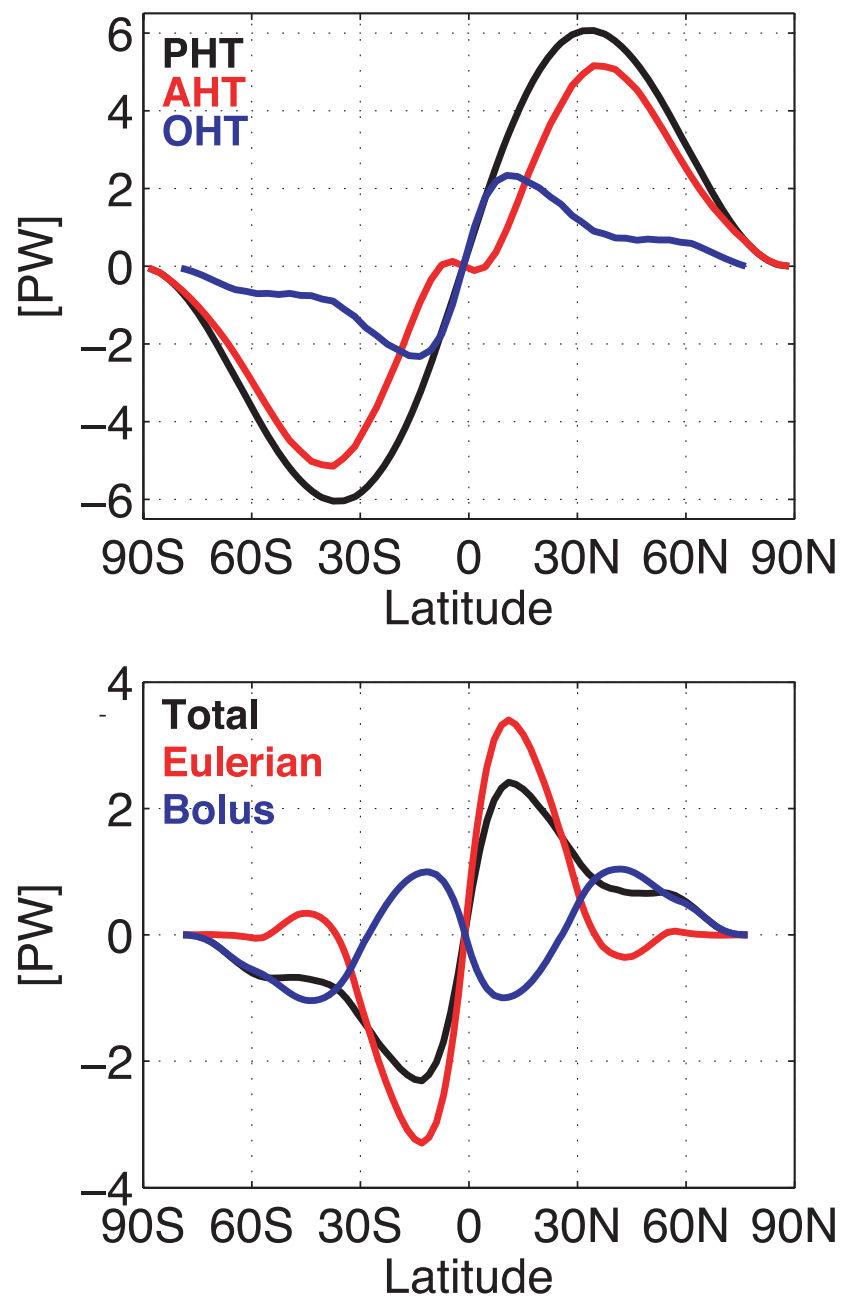

Fig. 16. Meridional heat transports in the Aquaworld experiment. The oceanic (OHT) and atmospheric (AHT) heat transports sum up to give a total, or planetary (PHT), transport of about 6 PW $\left(1 \mathrm{PW} \equiv 10^{15} \mathrm{~W}\right)$ in each hemisphere. The oceanic decomposition into an eulerian and eddy-driven or bolus component is shown in the bottom panel.

tions such as quasi-geostrophic models. Smith et al. (2006) and Marshall et al. (2007) used idealised coupled frameworks in a similar spirit.

As with any simplified framework, the model is subject to criticisms and it is also open to future improvements. It is important to understand what the model is capable of doing, and what is not. For example, the ice-albedo-cloud feedback is removed because of the fixed surface albedo and absence of clouds, and carbon-climate feedbacks are not possible with the present radiation scheme. However, given its limitations, the possible applications of the coupled model are manifold, from local air-sea interactions to the study of climate of extrasolar planets. 
Finally, we believe that ICCMp1 is a powerful tool for the study of ocean-atmosphere interactions and variability from interannual to centennial periods, with a close connection to the Earth's present day, and possibly past, climate. Also, ocean modellers might find useful to study the ocean and sea-ice components of the climate system when coupled to a simple, fast and yet dynamically interactive atmosphere.

Acknowledgements. We would like to thank Dargan Frierson for developing the simplified atmospheric physics packages, Stephen Garner for help with the Atmospheric model, and Chris Milly and Sergey Malyshev for assistance with the Land model. A special thanks to Stephen Griffies for his help and advice on Ocean modelling and development. Two anonymous reviewers provided useful suggestions to improve the paper. This work was funded by NOAA and NSF. RF was supported by the GFDL/AOS Postdoctoral Program.

\section{References}

Betts, A. K.: A new convective adjustment scheme. Part I: Observational and theoretical basis, Q. J. Roy. Meteorol. Soc., 112, 677-692, 1986.

Betts, A. K. and Miller, M. J.: A new convective adjustment scheme. Part II: Single column tests using GATE wave, BOMEX, and arctic air-mass data sets, Q. J. Roy. Meteorol. Soc., 112, 693709, 1986.

Delworth, T., Broccoli, A., Rosati, A., Stouffer, R., Balaji, V., Beesley, J., Cooke, W., Dixon, K., Dunne, J., Dunne, K., Durachta, J., Findell, K., Ginoux, P., Gnanadesikan, A., Gordon, C., Griffies, S., Gudegel, R., Harrison, M., Held, I., Hemler, R., Horowitz, L., Klein, S., Knutson, T., Kushner, P., Langenhorst, A., Lee, H.-C., Lin, S., Lu, L., Malyshev, S., Milly, P., Ramaswamy, V., Russel, J., Schwarxkopf, M., Shevliakova, E., Sirutis, J., Spelman, M., Stern, W., Winton, M., Wittenberg, A., Wyman, B., Zeng, F., and Zhang, R.: GFDL's CM2 global coupled climate models. Part I: Formulation and simulation characteristics, J. Climate, 19, 643-674, 2006.

Enderton, D. and Marshall, J.: Controls on the total dynamical heat transport of the atmosphere and oceans, J. Atmos. Sci., 66, 15931611, 2009.

Fanning, A. F. and Weaver, A. J.: A horizontal resolution and parameter sensitivity study of heat transport in an idealized coupled climate model, J. Climate, 10, 2469-2478, 1997.

Frierson, D. M. W.: Studies of the general circulation of the atmosphere with a simplified moist general circulation model, Ph.D. thesis, 2005.

Frierson, D. M. W.: The Dynamics of Idealized Convection Schemes and Their Effect on the Zonally Averaged Tropical Circulation, J. Atmos. Sci., 64, 1959-1976, 2007.

Frierson, D. M. W., Held, I. M., and Zurita-Gotor, P.: A GrayRadiation Aquaplanet Moist GCM. Part I: Static Stability and Eddy Scales, J. Atmos. Sci., 63, 2548-2566, 2006.

Frierson, D. M. W., Held, I. M., and Zurita-Gotor, P.: A grayradiation aquaplanet moist GCM. Part II: Energy transports in altered climates, J. Atmos. Sci., 64, 1680-1693, 2007.

Garner, S. T., Frierson, D. M. W., Held, I. M., Paulius, O. M., and Vallis, G. K.: Resolving convection in a global hypohydrostatic model, J. Atmos. Sci., 64, 2061-2075, 2007.
Gent, P. and McWilliams, J.: Isopycnal mixing in ocean circulation models, J. Phys. Oceanogr., 20, 150-155, 1990.

Griffies, S.: The Gent-McWilliams skew-flux, J. Phys. Oceanogr., 28, 831-841, 1998.

Griffies, S. M., Harrison, M. J., Pacanowski, R. C., and Rosati, A.: A technical guide to MOM4, Tech. Rep. GFDL Ocean Group No. 5, 2004.

Griffies, S. M., Gnanadesikan, A., Dixon, K. W., Dunne, J. P., Gerdes, R., Harrison, M. J., Rosati, A., Russell, J. L., Samuels, B. L., Spelman, M. J., Winton, M., and Zhang, R.: Formulation of an ocean model for global climate simulations, Ocean Sci., 1, 45-79, 2005, http://www.ocean-sci.net/1/45/2005/.

Hazeleger, W., Severijns, C., Haarsma, R., Selten, F., and Sterl, A.: SPEEDO - model description and validation of a flexible coupled model for climate studies, Tech. Rep. TR-257, 37 pp., 2003.

Held, I. M.: The Gap between Simulation and Understanding in Climate Modeling, B. Am. Meteorol. Soc., 86, 1609-1614, 2005.

Hogg, A., Dewar, W., Killworth, P., and Blundell, J.: A quasigeostrophic coupled model: Q-GCM, Mon. Weather Rev., 131, 2261-2278, 2003.

Kamenkovich, I. V., Marotzke, J., and Stone, P. H.: Factors affecting heat transport in an ocean general circulation model, J. Phys. Oceanogr., 30, 175-194, 2000a.

Kamenkovich, I. V., Sokolov, A. P., and Stone, P. H.: A coupled atmosphere-ocean model of intermediate complexity for climate change study, Tech. Rep. No.60, 2000 b.

Kamenkovich, I. V., Sokolov, A. P., and Stone, P. H.: An efficient climate model with a 3D ocean and a statistical-dynamical atmosphere, Clim. Dynam., 19, 585-598, 2002.

Kravtsov, S. and Ghil, M.: Interdecadal variability in a hybrid coupled ocean-atmosphere-sea-ice model, J. Phys. Oceanogr., 34, 1756-1775, 2004.

Kravtsov, S. and Robertson, A.: Midlatitude ocean-atmosphere interaction in an idealized coupled model, Clima. Dynam., 19, 693-711, 2002.

Kravtsov, S., Dewar, W. K., Berloff, P., McWilliams, J. C., and Ghil, M.: A highly nonlinear coupled mode of decadal variability in a mid-latitude ocean-atmosphere model, Dynam. Atmos. Oceans, 43(3-4), 123-150, 2007.

Kuhlbrodt, T., Griesel, A., Montoya, M., Levermann, A., Hofmann, A., and Rahmstorf, S.: On the driving processes of the Atlantic meridional overturning circulation, Rev. Geophys., 45, RG2001, doi:10.1029/2004RG000166, 2007.

Marshall, J., Ferreira, D., Campin, J. M., and Enderton, D.: Mean climate and variability of the atmosphere and ocean on an aquaplanet, J. Atmos. Sci., 64, 4270-4286, 2007.

Milly, P. C. D. and Shmakin, A. B.: Global modeling of land water and energy balances. Part I: The land dynamics (LaD) model, J. Hydrometeorol., 3, 283-299, 2002.

Mitchell, J. L., Pierrehumbert, R. T., Frierson, D. M. W., and Caballero, R.: The dynamics behind Titan's methane clouds, P. Natl. Acad. Sci., 103, 18421-18426, 2006.

Molteni, F.: Atmospheric simulations using a GCM with simplified physical parameterizations. I: model climatology and variability in multi-decadal experiments, Clim. Dynam., 20, 175-191, 2003.

Montoya, M., Griesel, A., Levermann, A., Mignot, J., Hofmann, M., Ganopolsky, A., and Rahmstorf, S.: The earth system model 
of intermediate complexity CLIMBER-3 $\alpha$. Part I: description and performance for present-day conditions, Clim. Dynam., 25, 237-263, 2005.

Opsteegh, J., Haarsma, R., Selten, F., and Kattenberg, A.: ECBILT, a dynamical alternative to mixed boundary conditions in ocean models, Tellus, 50A, 348-367, 1998.

Samelson, R. M.: Large-scale circulation with locally enhanced vertical mixing, J. Phys. Oceanogr., 28, 712-726, 1998.

Saravanan, R. and McWilliams, J. C.: Multiple equilibria, natural variability, and climate transitions in an idealized oceanatmsophere model, J. Climate, 8, 2296-2323, 1995.

Saravanan, R. and McWilliams, J. C.: Stochasticity and spatial resonance in interdecadal climate fluctuations, J. Climate, 10, 22992320, 1997.

Smith, R. S., Dubois, C., and Marotzke, J.: Global climate and ocean circulation on an aquaplanet ocean-atmosphere general circulation model, J. Climate, 19, 4719-4737, 2006.
Smith, R. S., Gregory, J. M., and Osprey, A.: A description of the FAMOUS (version XDBUA) climate model and control run, Geosci. Model Dev., 1, 53-68, 2008.

The GFDL Global Atmospheric Model Development Team: The New GFDL Global Atmosphere and Land Model AM2-LM2: Evaluation with Prescribed SST Simulations, J. Climate, 17, 4641-4673, 2005.

Trenberth, K. and Caron, J. M.: Estimates of meridional atmosphere and ocean heat transports, J. Climate, 14, 3433-3443, 2001.

Trenberth, K. E. and Stepaniak, D. P.: Covariability of components of poleward energy transports on seasonal and interannual timescales, J. Climate, 16, 3691-3705, 2003.

Winton, M.: A reformulated three-layer sea ice model, J. Atmos. Ocean. Tech., 17, 525-531, 2000. 